\title{
High Operating Temperature Liquid Metal Heat Transfer Fluids
}

\begin{tabular}{l}
$\begin{array}{l}\text { THE UNIVERSITY OF CALIFORNIA, } \\
\text { LOS ANGELES } \\
\text { THE UNIVERSITY OF CALIFORNIA, } \\
\text { BERKELEY } \\
\text { YALE UNIVERSITY }\end{array}$ \\
\begin{tabular}{ll} 
PROGRAM: & $\begin{array}{l}\text { 2012 Multidisciplinary University } \\
\text { Research Initiative (MURI): High } \\
\text { Operating Temperature (HOT) Fluids }\end{array}$ \\
\hline LOCATION: & California; Connecticut \\
\hline $\begin{array}{l}\text { AWARD } \\
\text { AMOUNT: }\end{array}$ & Up to \$5 million \\
PROJECT TERM: & 2012-2017
\end{tabular} \\
\hline
\end{tabular}

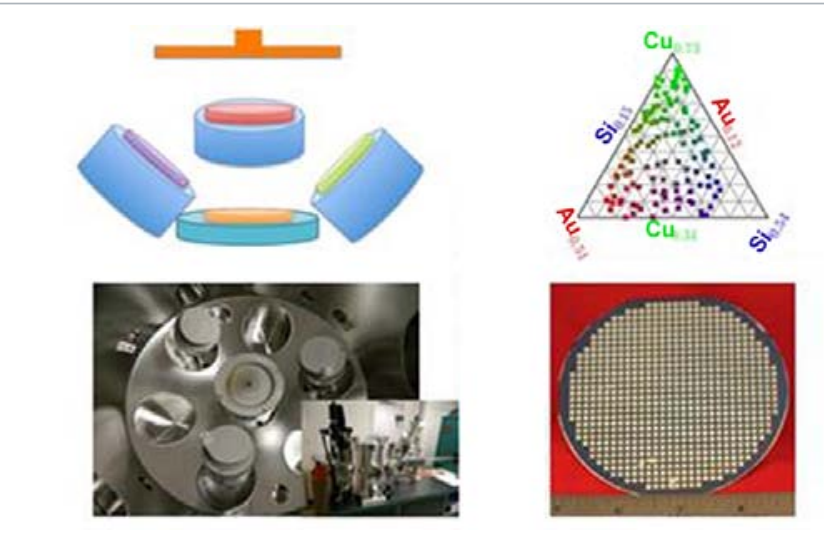

Combinatorial screening and high throughput characterization of materials will be used to identify, develop and demonstrate metal alloys that meet the MURI HOT Fluids targets suitable for CSP applications. Images from The University of California, Los Angeles, the University of California, Berkeley, and Yale University

\section{CONTACTS}

Project Leader:

Dr. Sungtaek Ju

just@seas.ucla.edu

\section{MOTIVATION}

Liquid metals have superior heat transport properties, including low vapor pressure, high thermal conductivity, and relatively low viscosity, that make them a natural candidate for many thermal applications in concentrating solar power (CSP) systems. However, a critical challenge in utilizing liquid metals at elevated temperatures is undesired reactions with structural materials or corrosion. To better realize the full potential of liquid metals as effective heat transfer fluids (HTFs), research efforts are needed to rapidly screen candidate materials, identify the most promising compositional spaces, and validate and improve material databases.

\section{PROJECT DESCRIPTION}

The UCLA-led project team is using a novel sputtering system to rapidly screen metal alloys with the desired thermophysical properties. The search space for the sputtering tool is being defined through modeling efforts, then being further refined by measurements taken with the rapid screening tool. The project team is using a combination of modeling along with a variety of property measurement and validation studies, such as hightemperature corrosion flow loops, to demonstrate that the metal alloys identified can meet all the needs of a CSP plant.

\section{IMPACT}

HTFs capable of meeting all of the project targets have the potential to be used in both current and next-generation CSP technologies. This fluid would also be technology independent, meaning the fluid could potentially be used in parabolic trough, linear Fresnel, or power tower technology. A successful candidate fluid would also allow for the reduction of the levelized cost of energy by increasing the operating temperature for the CSP plant power cycle, which would increase thermal-to-electric conversion efficiency. Moreover, the HOT fluids derived as part of the program will have a broader relevance to other fields as well.

For more information, visit the project page at: www.solar.energy.gov/sunshot/muri_ucla.html. 